\title{
Distal phalanx amputation with delayed presentation and successful reconstruction with reposition and flap after 2 weeks
}

\author{
Jefferson Braga-Silva, Renato Franz Matta Ramos ${ }^{1}$, Gabriela Meirelles Marchese ${ }^{2}$, \\ Pedro Salomao Piccinini ${ }^{1}$ \\ Hand and Reconstructive Microsurgery Service, Hospital Sao Lucas Medical School, Pontifical Catholic University of Rio \\ Grande do Sul, ${ }^{1}$ Hospital Sao Lucas, Pontifical Catholic University of Rio Grande do Sul, ${ }^{2}$ Pontifical Catholic University of Rio \\ Grande do Sul, Porto Alegre, Rio Grande do Sul, Brazil
}

Address for correspondence: Dr. Jefferson Braga-Silva, Pontifical Catholic University of Rio Grande do Sul, Avenida Ipiranga 6690, Suite 216, Porto Alegre, Rio Grande do Sul, Brazil. E-mail: jeffmao@terra.com.br

\section{ABSTRACT}

Traumatic finger amputations are common, causing significant functional and cosmetic deficits. Microsurgical replantation techniques are the mainstay of treatment for most such injuries although they require adequate conservation of the amputated segment for a successful result. In distal finger amputations, replantation is the procedure of choice, as long as the amputated fragment is viable. If replantation is not an option, reposition + flap using a neurovascular flap can be an efficient option, as this offers improved skin coverage. To the best of our knowledge, this case illustrates the longest cold ischaemic time with a successful outcome.

\section{KEY WORDS}

Amputation; fingertip; hand; reconstruction; trauma

\section{INTRODUCTION}

istal fingertip trauma is a common condition in the emergency department. We present an unusual case in which a patient presented to our hand surgery service 15 days after injury, and reconstruction was performed with reposition + flap, with good functional and cosmetic outcomes.

\begin{tabular}{|l|l|}
\hline \multicolumn{2}{|c|}{ Access this article online } \\
\hline Quick Response Code: & Website: \\
\hline & www.ijps.org \\
\cline { 2 - 2 } & Dol: \\
\hline
\end{tabular}

\section{CASE REPORT}

A 55-year-old woman presented to an outside facility after amputation of the distal phalanx of the ring finger after accidental knife injury. Primary closure of the stump was performed with 4-0 nylon and compression dressing.

This is an open access article distributed under the terms of the Creative Commons Attribution-NonCommercial-ShareAlike 3.0 License, which allows others to remix, tweak, and build upon the work non-commercially, as long as the author is credited and the new creations are licensed under the identical terms.

For reprints contact: reprints@medknow.com

How to cite this article: Braga-Silva J, Ramos RF, Marchese GM, Piccinini PS. Distal phalanx amputation with delayed presentation and successful reconstruction with reposition and flap after 2 weeks. Indian J Plast Surg 2016;49:419-21. 
The patient returned home and placed the amputated segment in a sealed glass jar at $4^{\circ} \mathrm{C}$ in her refrigerator. Dressing changes were performed at a public clinic every $48 \mathrm{~h}$.

Fifteen days after initial injury, she presented to our service and inquired about the possibility of replantation. The senior author explained to her about his experience with reposition + flap $(\mathrm{R}+\mathrm{F})$; however, he usually performed this on the day of injury, rather than 2 weeks later.

The patient brought the amputated fragment to the office [Figure 1]; it seemed viable, and the segment to be replaced (nail complex and distal bone fragment of the distal phalanx) was in good overall condition, despite the prolonged time from injury. After careful evaluation of the amputated fragment and discussion about risks and benefits with the patient, decision was made for surgery. Surgery was performed as an outpatient procedure, under local anaesthetic block. The entire distal volar segment was resected, and reposition was performed with a homodigital island advancement flap. Bone fixation was performed with a Kirschner wire. The patient progressed well postoperatively, with very good functional and cosmetic results [Figure 2]. There were no complications such as hook nail.

At 8-year follow-up, the patient was seen in the office, with only minimal functional deficits (range of motion 20-70') [Figure 3], and X-ray demonstrating adequate consolidation [Figure 4]. Semmes-Weinstein monofilament test and two-point discrimination with standard callipers were both normal. The patient had no complaints of allodynia, hyper- or hypoalgesia and heat or cold intolerance. On a visual analogue scale, the patient was satisfied with the reconstruction, rating it 8 out of 10 (1-10; 1 - poor result, 10 - best result).

When microsurgical repair of the neurovascular pedicle is impossible, $\mathrm{R}+\mathrm{F}$ may be an adequate choice, in an attempt to preserve finger size, the nail bed complex and sensation [Figures 5-7].

$R+F$ was described by Mantero in 1975. First, the amputated segment was simply repositioned. After 15 days, nonviable tissue was debrided, and a volar advancement flap was used to cover the distal phalanx. This technique had a high rate of osteitis with subsequent resorption of the distal phalanx and was thus

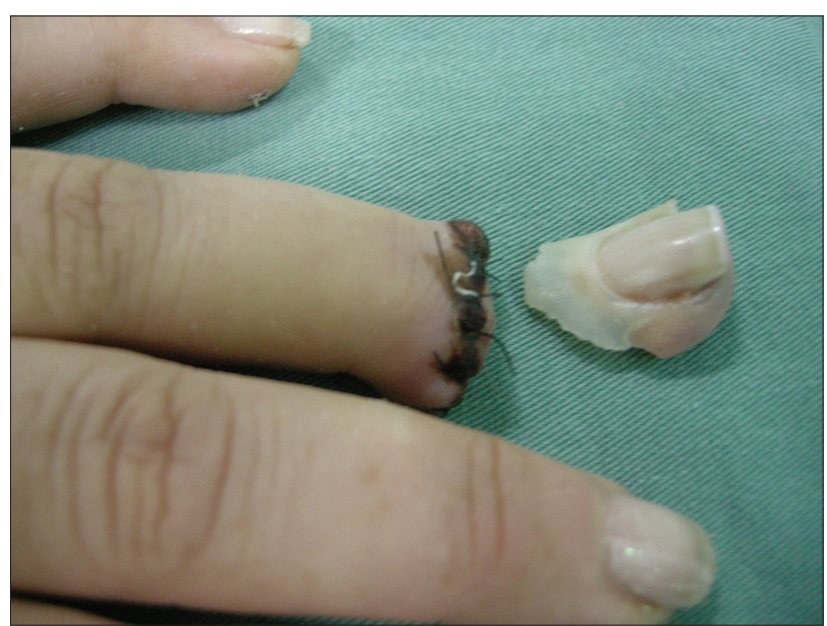

Figure 1: Amputated distal ring finger segment and stump at initial presentation to our service, 2 weeks after injury

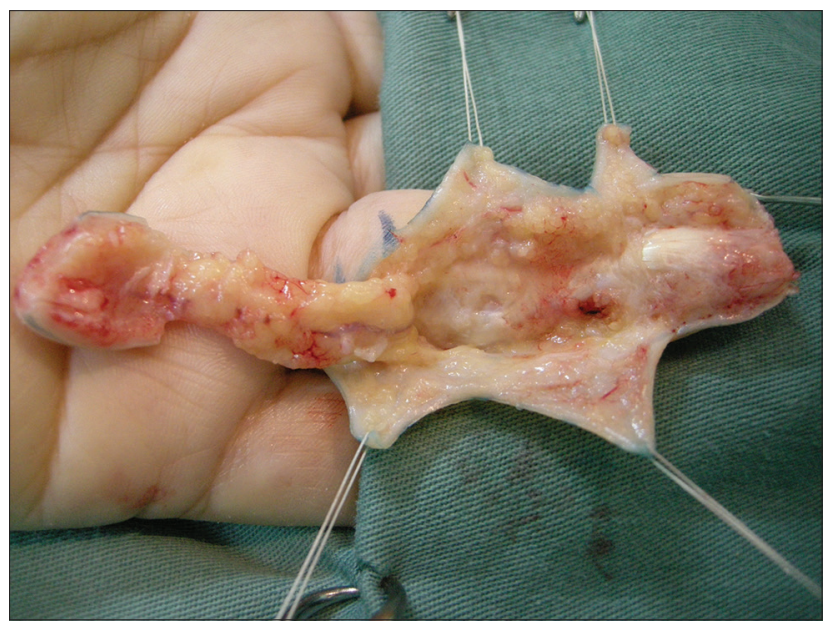

Figure 2: Homodigital volar island advancement flap raised

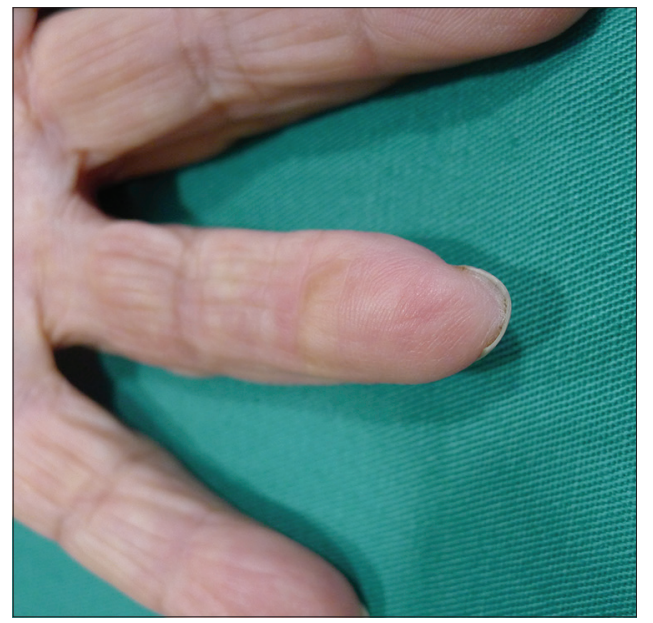

Figure 3: Final result after reposition + flap at 8-year and 5-month follow-up

abandoned.$^{[1,2]}$ In 1992, Foucher et al.$^{[3]}$ published a series of cases, in which tissue from the palmar surface of the amputated segment was excised and an advancement 


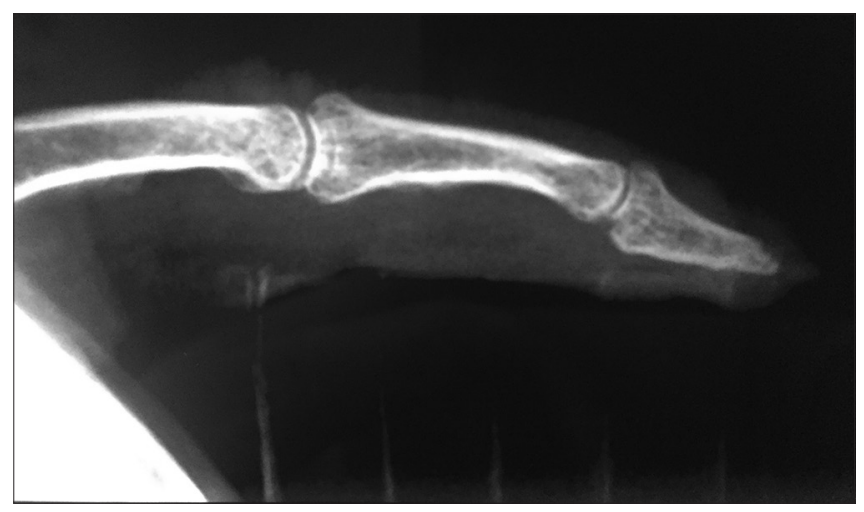

Figure 4: X-ray at 8-year and 5-month follow-up demonstrating adequate bone consolidation

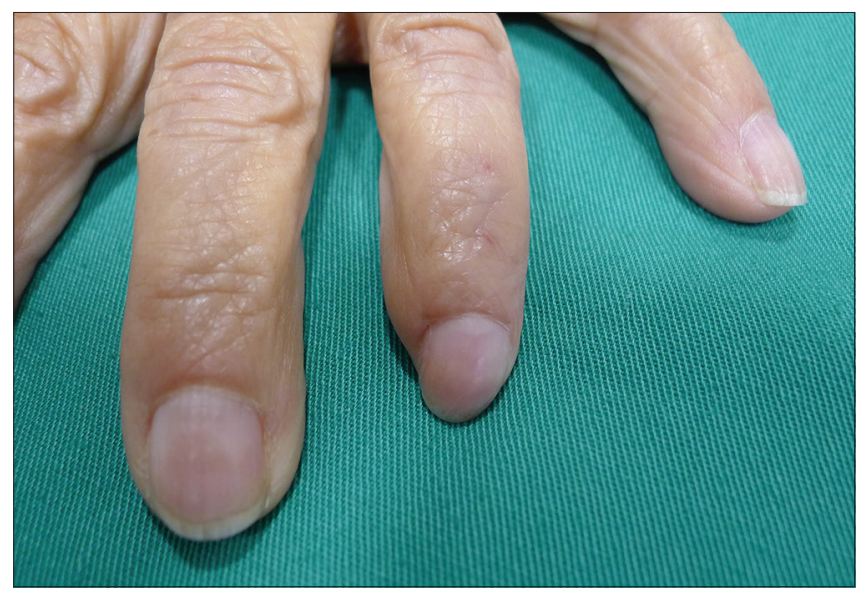

Figure 6: Adequate cosmetic result in comparison to $5^{\text {th }}$ and $4^{\text {th }}$ fingers

flap was performed in the emergency room. Multiple authors have since published on $\mathrm{R}+\mathrm{F}$, with variable results. ${ }^{[4]}$

Digital replants have proven successful after up to $33 \mathrm{~h}$ of warm ischaemia and $94 \mathrm{~h}$ of cold preservation. Replantation after such prolonged ischaemic times, however, should only be attempted in a very select number of cases, due to the increased risks of necrosis, infection and thrombosis.

Multiple recent studies have shown conflicting data with regard to the influence of ischaemic time on outcomes in digital replantation.

This case, in line with the latest literature, illustrates that we may need to review the significance of the role played by ischaemic time on survival and functional outcomes of distal finger amputation; $\mathrm{R}+\mathrm{F}$ is an option which should be in the hand surgeon's armamentarium.

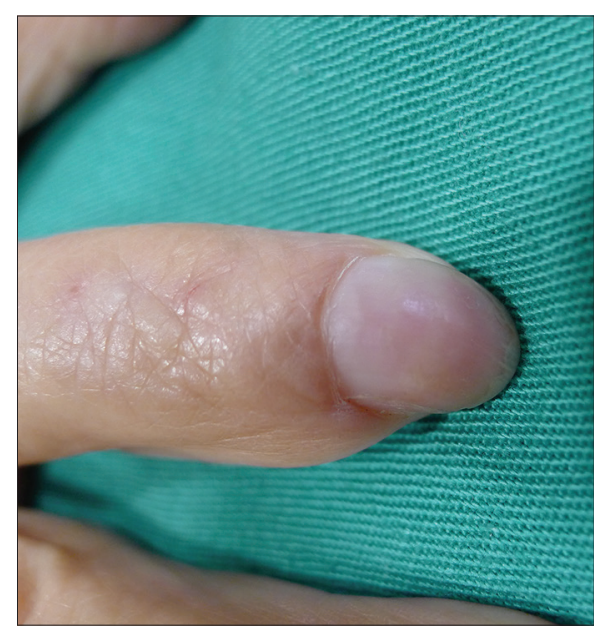

Figure 5: Close-up of reconstructed fingertip at eight years, dorsal aspect with intact nail

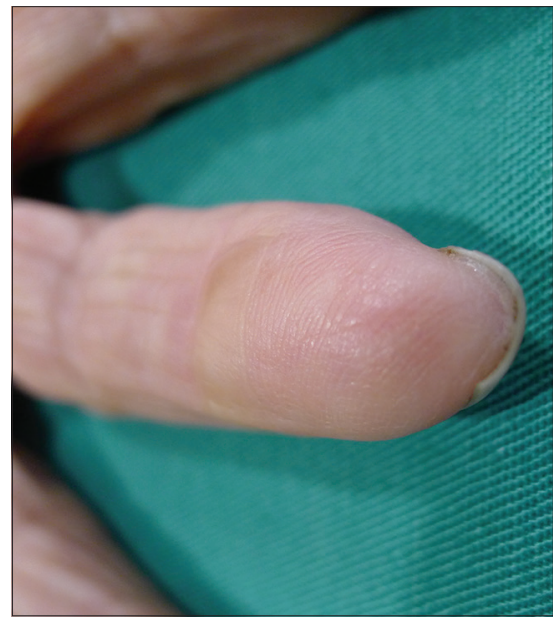

Figure 7: Volar aspect of the reconstructed $4^{\text {th }}$ finger demonstrates absence of hook nail

\section{Financial support and sponsorship} Nil.

\section{Conflicts of interest}

There are no conflicts of interest.

\section{REFERENCES}

1. Mantero R, Bertolotti P. Reimplantation of the finger tips using a cross-finger technique (author's transl). Ann Chir 1975;29:1019-23.

2. Robert N, Chassat R, Couturier C, Delpit X, Masmejean E. "Reposition-flap": A therapeutic alternative in fingertips amputations. Ann Chir Plast Esthet 2015;60:299-304.

3. Foucher G, Braga Da Silva J, Boulas J. "Reposition-flap" technique in amputation of the finger tip. Apropos of a series of 21 cases. Ann Chir Plast Esthet 1992;37:438-42.

4. Braga-Silva J, Jaeger M. Repositioning and flap placement in fingertip injuries. Ann Plast Surg 2001;47:60-3. 